\title{
Reactions to Terror Attacks: A Heuristic Model
}

\author{
Paul M. Sniderman \\ Stanford University
}

Michael Bang Petersen

Aarhus University

\author{
Rune Slothuus \\ Aarhus University
}

Rune Stubager

Aarhus University

Philip Petrov

Stanford University

\begin{abstract}
What are the signature features of the reactions of mass publics to terrorist attacks? We argue that the available empirical evidence suggests a general pattern of reactions: The peaks of mass reactions to terrorist attacks are limited in size and duration and their end states marked by a return to baselines values of tolerance. We label this perturbation effects. In this article, we review the available evidence for perturbation effects, build a heuristic model of such effects and provide an explanation of their characteristic pattern, combing theories of emotional arousal and opinion leadership. Finally, we relate the overlooked existence of perturbation effects to widespread fears about the frailty of democratic norms in the face of mass terrorism.
\end{abstract}

KEY WORDS: public opinion, terrorism, tolerance, democracy, immigration

Do majority citizens prioritize national security at the expense of civil liberties in response to terror attacks? Do they stigmatize Muslim immigrants, blaming them for the carnage of Islamic terrorists? Vital questions, but our objective is not an inventory of empirical findings. It is to contribute to the development of theory. How should reactions of mass publics to terror attacks in contemporary liberal democracies be modeled? What are the principal mechanisms? How are they related one to another and to outcomes? What are the signature features of the reactions of mass publics to terror attacks?

It is our belief that research on the reactions of mass publics to terror attacks has made more progress than has been recognized. Empirical results, we will suggest, point to a common, perhaps even characteristic, pattern of reactions: The peaks of mass reactions to terror attacks are limited in 
size and duration and their end states marked by a return to baselines values. A perturbation effect we will label this.

Appreciation of perturbation effects has the virtue of addressing the normative concern that motivates the study of mass reactions to terror attacks. Mass reactions to terror attacks, it is feared, represent a potential Achilles heel of liberal democracies. There are solid reasons for this fear. No one believes that mass publics have a deeply grounded commitment to democratic values, and their susceptibility to demagoguery is evident. The risk of an eruption of Islamophobia in response to atrocities committed by Islamic terrorists is patent. Concerns about the risks of nativism and the gains of anti-immigration parties have deepened our understanding of how things can go off the rails with respect to civil rights in large-scale democracies. All the more reason, then, to ask for greater effort in investigating how democracies can stay on track.

Working through the causal logic of a simple model of perturbation effects also has some substantive and methodological benefits, we believe. This is a heuristic effort benefiting from the primary research of others. Beyond acknowledging our debt, we want to call particular attention to the constraints under which they have worked. Virtually without exception, studies bearing on terror attacks were either designed for other purposes or fielded sometime after the attack. Nevertheless, as studies have accumulated, broad similarities in results can be made out. We shall highlight two: a peak limited in size and duration and an end signaled by a return to baseline values. Our objectives are to call attention to evidence consistent with this pattern of peak and end and then to consider why mass reactions take the form that they have.

\section{An Empirical Prelude}

Our starting point is an overlooked puzzle. Over the last two decades, the issues of immigration and immigrants have fired up resentment and nativist backlash in Western Europe. Year after year, there has been crisis after crisis. It has been a gathering storm. Major changes in public attitudes towards immigrants would seem a certain bet. Results, however, suggest otherwise.

Taking advantage of the European Social Survey, we have calculated trends in attitudes towards immigrants from 2002 through 2016. In all, eight countries are covered-Germany, Denmark, Spain, France, Great Britain, the Netherlands, Sweden, and Norway. All are countries grappling with the inclusion of immigrants. The countries themselves, though, differ in ways manifestly relevant to the issue of immigrants - among them, the scale and timing of immigration; social and economic resources available to the countries cope with the problems; and their political culture and self-conception.

The European Social Survey asked, inter alia, a trio of questions in every country: whether [country] is made a worse or better place to live by the arrival of people from other countries; whether [country's] cultural life is generally undermined or enriched by people coming from other countries; whether it is generally good or bad for [country]'s economy that people come from other countries. Figure 1A shows responses to the first question, whether immigrants make the country a better or worse place to live; Figure 1B shows responses to the second question, whether immigrants enrich the culture; and Figure $1 \mathrm{C}$ responses to the third question, whether immigrants are good or bad for the economy. Higher levels indicate more hostility towards immigrants; lower levels less hostility.

The pattern in all eight countries is strikingly similar; indeed, for all practical purposes identical. In country after country, on question after question, the lines do not spike or plunge; indeed, they scarcely move up or dip down. They are flat or as near makes no difference. It is perfectly possible, provided one is willing to squint, to detect an upward "trend." To our eyes, Norway is the best example. Scored between 0 and 10, the mean response in Norway was 4.79 (SE 1.9) in 2002 and 5.62 (SE 2.0) in 2016. If you would like to conclude that attitudes are more 
negative at the end than at the beginning, we would not argue. Were you to claim that there had been a marked or pronounced or substantial increase in hostility towards immigrants, we would have to beg to differ.

The years that Figures 1A, 1B, and 1C cover are years of unprecedented attacks by Islamic terrorists. The 2002 Bali bombing killed 202 and injured 240; the London bombings in 2005 resulted in 53 deaths and injured more than 700 injuries; the Paris massacre in 2015 killed 137 and injured 368. To be clear, scale is not a necessary condition of impact. The assassination in the Netherlands of Theo van Gogh in 2004 stunned a nation. Yet attitudes of national majorities towards immigrants in 2016 remained pretty much the same as they had been in 2002. This is a headline result; yet we are not aware of prior research has reporting it, nor of a theory from which it would or could have been deduced.

A second surprise: immediate reactions to terrorist attacks. Survey research has much to recommend it, but speed is not its strong suit. Studies of responses to terror that we shall review typically rely on surveys designed to assess public opinion for other purposes or fielded, because of the

A

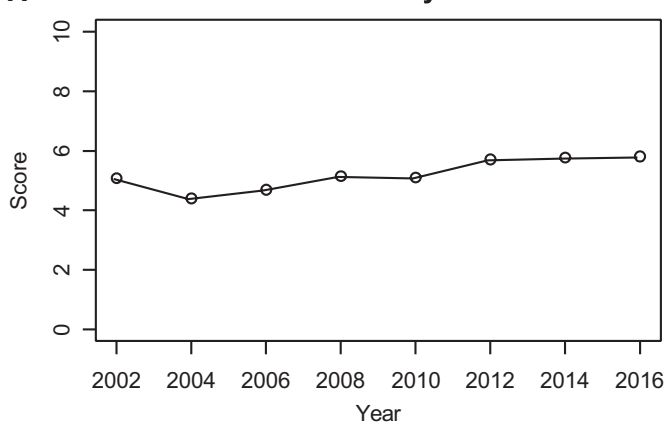

Netherlands

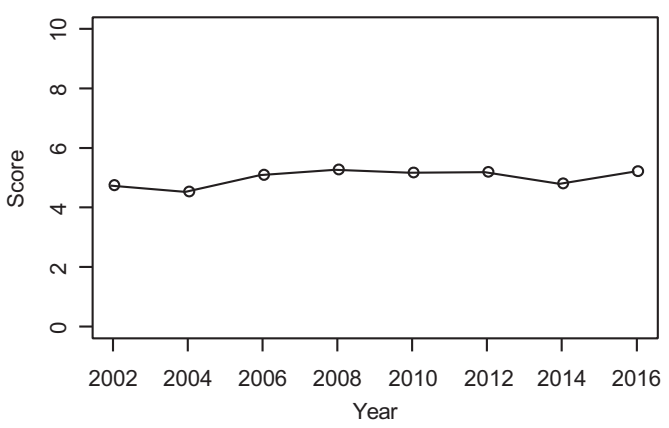

Spain

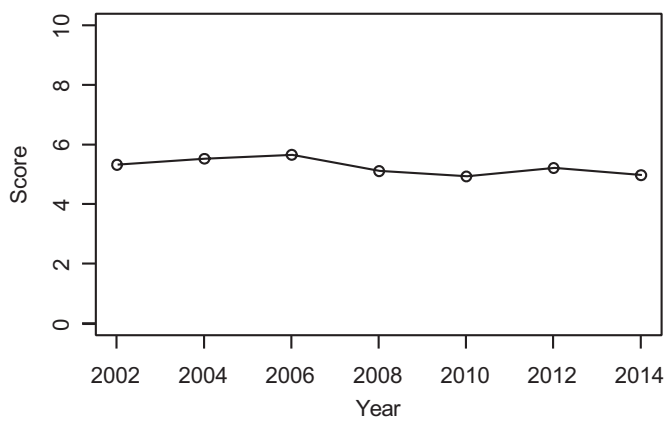

Great Britain

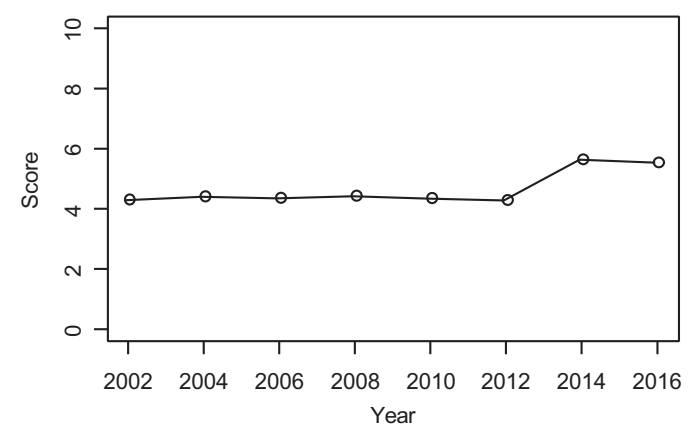

Norway

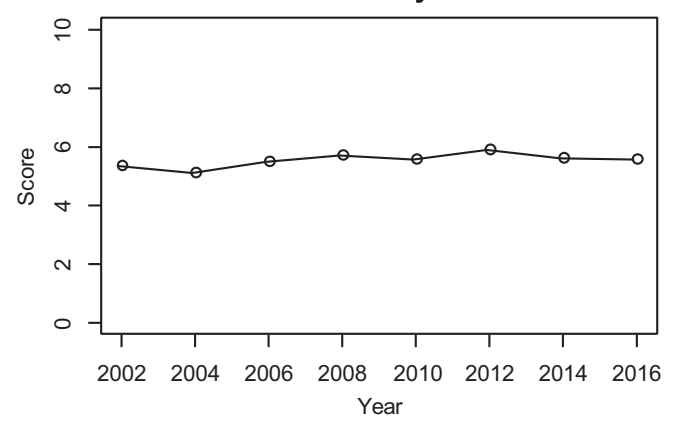

Sweden

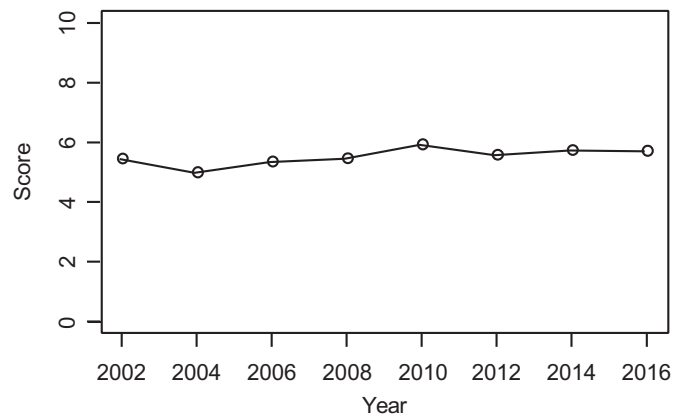


B

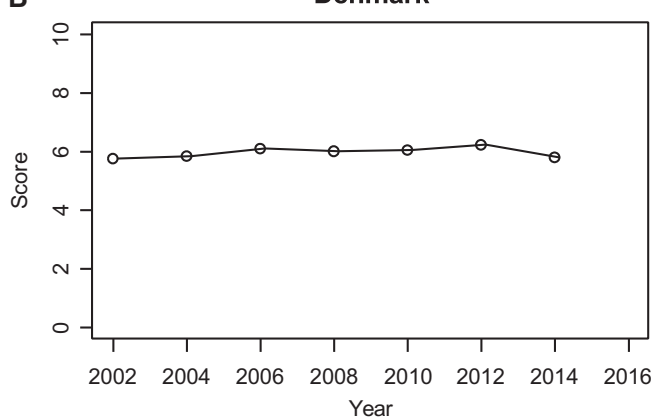

Germany

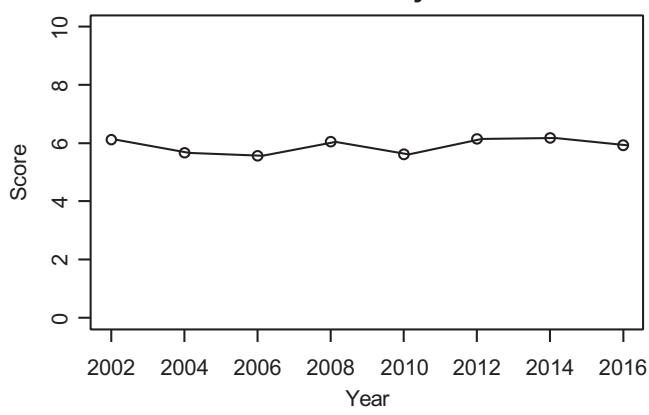

Netherlands

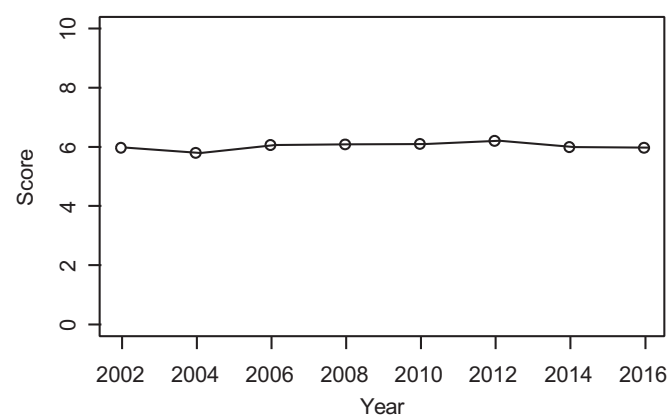

Spain

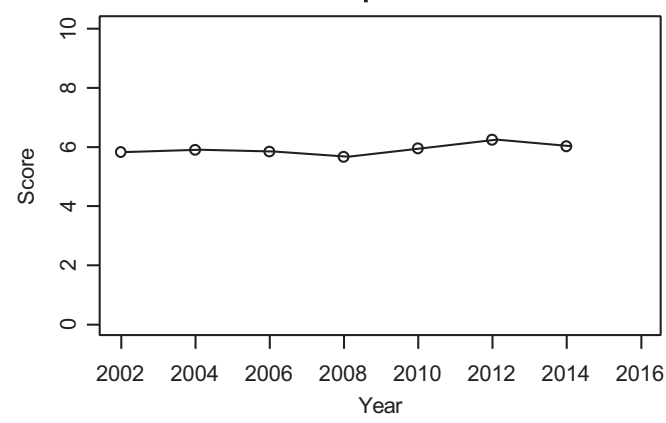

France

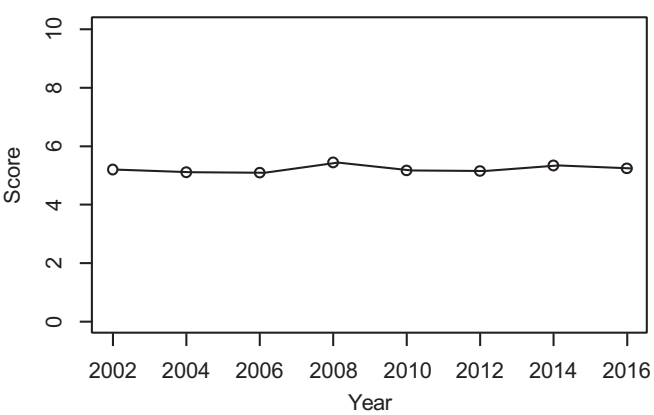

Great Britain

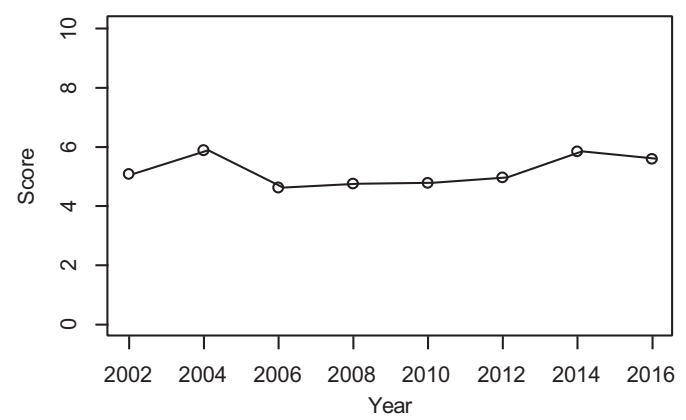

Norway

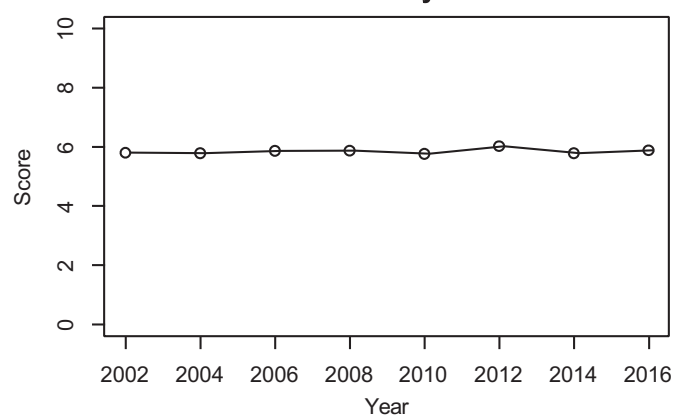

Sweden

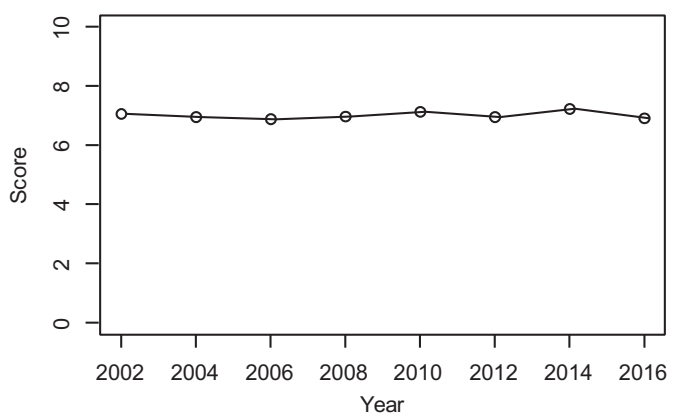


C

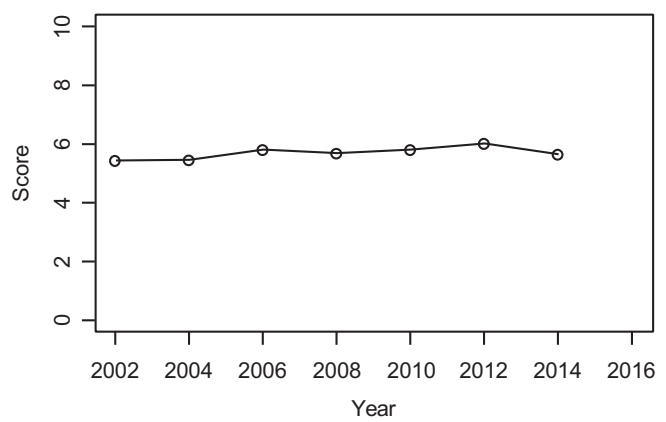

Germany

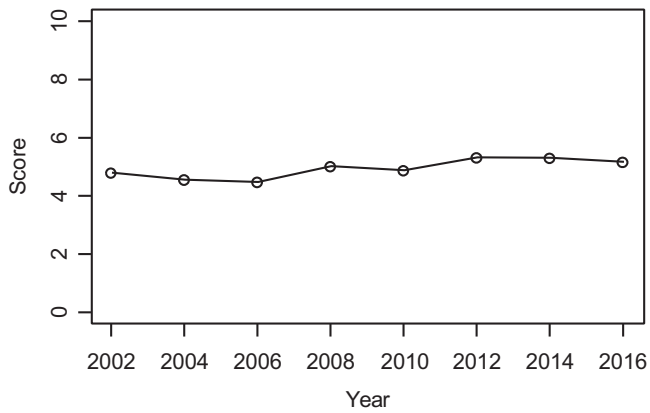

Netherlands

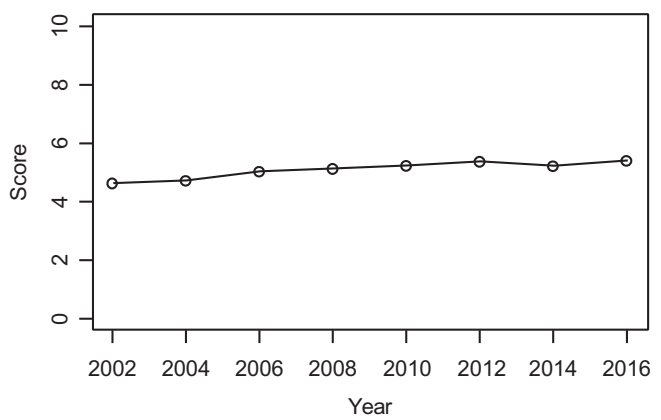

Spain

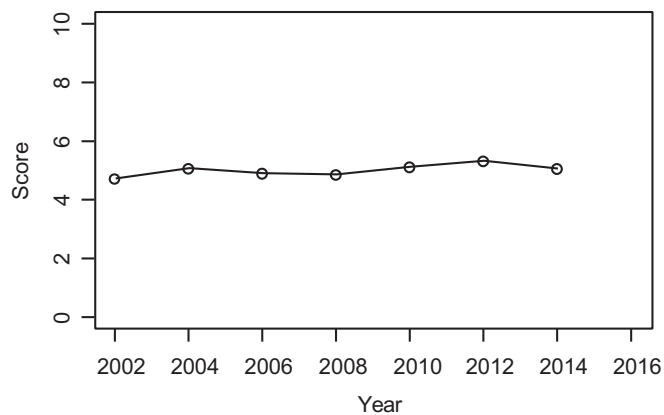

France

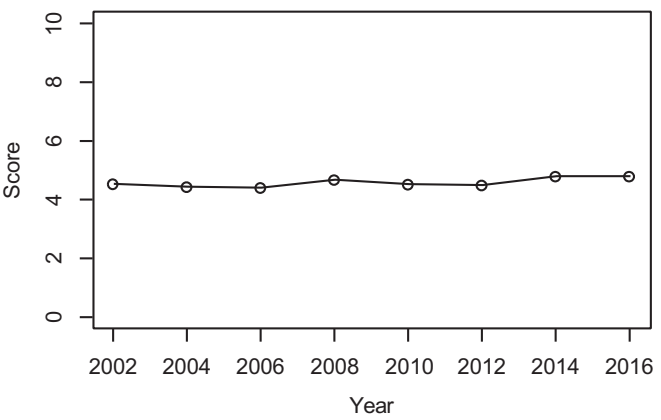

Great Britain

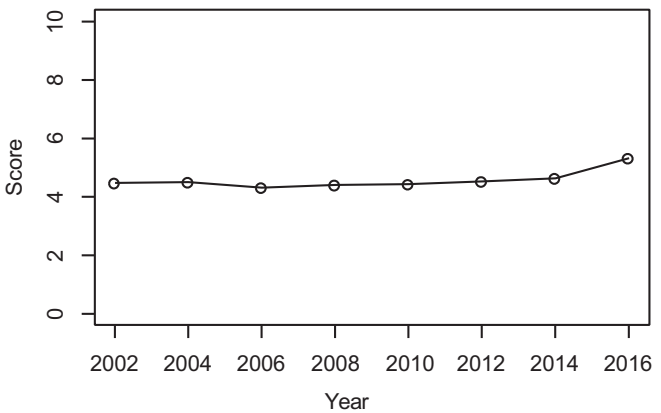

Norway

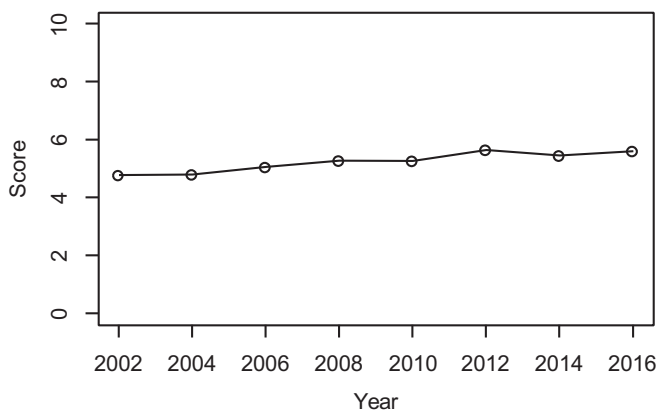

Sweden

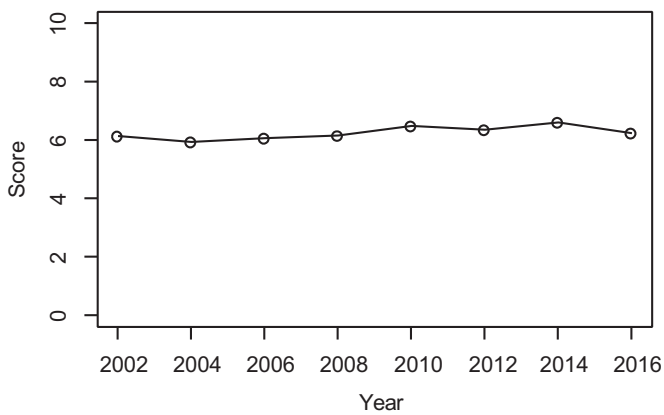

Figure 1. Graphs are based on European Social Surveys collected between 2002 and 2016 in Germany, Denmark, Spain, France, Great Britain, the Netherlands, Sweden, and Norway. Panel A displays within-country developments in responses to the question "whether [country] is made a worse or better place to live by the arrival of people from other countries"; Panel B displays within-country developments in responses to the question "whether [country's] cultural life is generally undermined or enriched by people coming from other"; and Panel C displays within-country developments in responses to the question "whether it is generally good or bad for [country]'s economy that people come from other countries." Entries are mean responses, on a scale from 0 to 10 , with higher levels indicating more hostility towards immigrants. 
up-front requirements of large-scale public opinion surveys, months or more after a terror attack. To assess immediate reactions to terror, reactions say rather than months after an attack, we have exploited the last resort of science, luck.

A study of Islamophobia in Denmark had begun on February 7, 2015. A questionnaire had been vetted and a pilot study had been completed $(N=155)$. On the afternoon of February 14,2015 , at a popular civic center in Copenhagen part way through a meeting featuring, among others, a Swedish artist who had depicted the prophet Mohammed as a dog, an assassin opened fire, shooting and killing a bystander. On February 15, shortly after midnight, as family and friends celebrated a bar mitzvah, the same assassin shot and killed a guard outside the largest Danish synagogue. On February 17, two days after the murders, the study went full out $(N=1005) .{ }^{1}$ It had been designed to investigate levels of support for inclusion of Muslims, focusing on three issues: recognition of the worth of Muslim cultural values and traditions; acknowledging the new diversity of Denmark in school textbooks; and willingness to allow construction of mosques. A fourth measure, more generic but useful all the same, assessed general attitudes towards immigration.

Table 1 presents means, pre- and postterrorist attack, for the four measures. The degree of similarity before and after the attack is, if anything, unsettling. The mean for the school textbook item acknowledging the new diversity of Danish culture before the murders in Copenhagen was .48 ( $S E$ .03 ); the week after, .46. (SE .01). Results for the three other items are equally unequivocal. Danish attitudes towards Muslims and recognition of Islam in Denmark are not, on average, more negative after the murders in Copenhagen than before. In short, the results in Table 1 show no evidence of a backlash in the immediate aftermath of a terror attack. A suggestive result, though of course not a dispositive result. ${ }^{2}$

A follow-up study was done. The design is the same but on a larger scale. A survey of attitudes towards Muslim was conducted in Great Britain on November 10-12 $(N=1,707)$. The Paris massacre occurred on November 13. The first of these surveys, by chance, went into the field three days before the massacre. This survey was fielded to a nationally representative sample of 1,707 individuals using the YouGov online panel between the November 10 and 12. To assess immediate reactions to terror on an exceptional scale, a second survey, duplicating the entire content of the first, was fielded four days after the attacks, on November 17-18, to a fresh sample of 1,621 respondents. ${ }^{3}$ Although these surveys were fielded in Britain, and not France, the terror attacks in Paris completely dominated news coverage in the intervening days in Britain.

Table 2 reports scores immediately before the Paris massacre (column 1), scores immediately after it (column 2), and the difference between the two (column 3) for five measures of attitudes towards Muslims and one measure of attitudes towards immigration in Britain. The results are striking. The difference between how British felt about Muslims and immigration before and immediately after the Paris massacre was either statistically insignificant or trivial.

\footnotetext{
${ }^{1}$ We also report on this study elsewhere (Sniderman et al., n.d.).

${ }^{2}$ It is worth noting the striking similarity of this absence of a backlash towards Muslims to a similar pattern of findings in our study of Danes' reactions to a public crisis over the place of Islam in Danish life, what we and others referred to as The Cartoon Crisis (Sniderman, Petersen, Slothuus, \& Stubager, 2014). In response to publication by a Danish newspaper of cartoons depicting the prophet Mohammed, governments of Muslim majority countries demanded an apology from the Danish prime minister and a pledge from Danish newspapers not ever to publish "offensive" matter again; the storm turned into the worst foreign policy crisis of Denmark since World War Two. Even as the storm over publication of the cartoons intensified in early 2006, however, Danes drew a sharp distinction on issues of civil liberties between Islamic fundamentalists and ordinary Muslims. Still more strikingly, Danes drew no distinction between Muslims and fellow Danes, and just as important, the support for the civil liberties of Muslims was at least as strong and stable at the height of the crisis as when the crisis had later disappeared from the public agenda (Sniderman et al. 2014: Chap. 2).

${ }^{3} \mathrm{~A}$ total of 106 respondents from the first wave were randomly selected into the second wave. As receiving identical surveys twice in quick succession could have influenced response patterns, these responses were excluded from our analysis of the postattack survey.
} 
Table 1. Tolerance Before and After Copenhagen Shootings

\begin{tabular}{lccccc}
\hline & $\begin{array}{c}\text { Before } \\
\text { Shootings }\end{array}$ & $\begin{array}{c}\text { After } \\
\text { Shootings }\end{array}$ & $\begin{array}{c}\text { Difference } \\
(\boldsymbol{p} \text {-value in } \\
\text { parentheses })\end{array}$ & $\boldsymbol{N}$ : Before & $\boldsymbol{N}$ : After \\
\hline Immigration poses a serious threat & .46 & .44 & $-.03(0.397)$ & 151 & 977 \\
Muslim group allowed to build mosque & .53 & .50 & $-.03(0.512)$ & 137 & 913 \\
Respect/protect Muslim traditions and culture & .49 & .45 & $-.05(0.153)$ & 150 & 968 \\
School textbooks should reflect diversity & .46 & .44 & $-.02(0.380)$ & 147 & 962 \\
Index of all four tolerance items & .49 & .45 & $-.05(0.193)$ & 128 & 854 \\
\hline
\end{tabular}

Note. Entries are mean tolerance, measured on a $0-1$ scale, with higher values indicate greater tolerance. "Don't know" is coded as missing.

Table 2. Attitudes to Outgroups in Britain Before and After Paris Terror Attacks (0-1 scales)

\begin{tabular}{|c|c|c|c|}
\hline Item & Preterror Attack Mean & Postterror Attack Mean & Difference \\
\hline \multicolumn{4}{|l|}{ Views of Muslims in Britain } \\
\hline Muslims have a lot to offer British culture & 0.48 & 0.48 & n.c. \\
\hline Muslims in Britain respect culture of others & 0.37 & 0.40 & +0.03 \\
\hline $\begin{array}{l}\text { European and Muslim ways of life } \\
\text { incompatible }\end{array}$ & 0.61 & 0.60 & -0.01 \\
\hline $\begin{array}{l}\text { Muslims in Britain raise their children in } \\
\text { authoritarian manner }\end{array}$ & 0.61 & 0.60 & -0.01 \\
\hline Muslim men dominate their women & 0.79 & 0.78 & -0.01 \\
\hline \multicolumn{4}{|l|}{ Views of Immigration in Britain } \\
\hline $\begin{array}{l}\text { Immigrants pose a serious threat to our } \\
\text { national character }\end{array}$ & 0.67 & 0.67 & n.c. \\
\hline \multicolumn{4}{|c|}{ Views of Immigrants and Ethnic Minorities in France } \\
\hline $\begin{array}{l}\text { Allow how many immigrants from different } \\
\text { ethnic group to majority }\end{array}$ & $\mathbf{0 . 5 3}$ & 0.58 & +0.05 \\
\hline $\begin{array}{l}\text { Allow how many immigrants from poorer } \\
\text { countries outside Europe }\end{array}$ & 0.47 & 0.53 & +0.06 \\
\hline Allow how many Muslims into France & 0.54 & 0.60 & +0.06 \\
\hline Cultural life enriched by immigrants & 0.53 & 0.57 & +0.04 \\
\hline Immigrants make France a better place to live & 0.47 & 0.51 & +0.04 \\
\hline Qualification for immigrants: be Christian & 0.27 & 0.25 & -0.02 \\
\hline Qualification for immigrants: be white & 0.17 & 0.15 & -0.02 \\
\hline $\begin{array}{l}\text { Government should be generous in assessing } \\
\text { asylum seeker claims }\end{array}$ & 0.64 & 0.63 & -0.01 \\
\hline
\end{tabular}

To be clear, we are far from suggesting that terror attacks are nonevents. Past research has provided clear evidence of the impact of terrorist attacks in foreign but closely related countries can be with, for example, the $9 / 11$ terror attacks on U.S. soil increasing the frequency of post-traumatic stress disorders in European countries (Hansen et al., 2016). But these two studies bring out a neglected feature of public opinion in the face of repeated terror attacks, notably, the inertia of attitudes towards immigrants including Muslim immigrants. ${ }^{4}$ Inertia does suggest a new perspective from which to view research on mass reactions to terror attacks.

\footnotetext{
${ }^{4}$ Bonilla and Grimmer (2013), in an innovative study, demonstrate that terror alerts in the United States, though raising citizens' estimates of the likelihood of an attack, have minimal effect on their political preferences, including presidential popularity, foreign intervention, or willingness to restrict civil liberties.
} 


\section{Framework Findings}

\section{$9 / 11$}

Davis's (2007) three-wave panel survey provides a portrait of mass reactions to 9/11. Interviewing for the first wave began within three months of the attack; the second wave, 12 months after the first; the third wave, 15 months after the second. ${ }^{5}$

A wide array of attitudes towards civil liberties was covered, such as criticism of the government by school-teacher, detention of noncitizens, guilt by association, national identification cards, nonviolent protest, racial profiling, search and seizure, wiretapping, and nonviolent protest. Issue by issue, mass support for civil liberties was essentially the same over the period as a whole. ${ }^{6}$ Moreover, when there was a difference between interview waves, in every instance but one, it took the form of an increase-not a decrease-in support for civil liberties (as to the exception, support for civil liberties had rebounded by the final wave). Minimal variation over this period in levels of support for civil liberties is the project's signature finding.

This is not an idiosyncratic finding. Summarizing the results of numerous commercial poles, Best, Krueger, and Ladewig (2006) report an initial willingness of the general public to back increased government investigative powers after $9 / 11$, followed by decline in support for most forms of surveillance (Best \& Ladewig 2006; Jenkins-Smith \& Herron, 2005). Similarly, Jenkins-Smith and Herron (2005) found a decrease in support for restrictions on speech within a year after 9/11. These studies suggest that mass reactions to $9 / 11$ were restrained and short-lived.

The 9/11 study results are not evidence that it is unnecessary, still less, that it is unwise, to be alert to risks or danger of overvaluing security and safety as against rights and liberties. The risks and dangers are real. Legislation (e.g., the Patriot Act) curbing civil liberties was enacted in response to $9 / 11$; wiretapping and email surveillance, among other intrusions, were expanded also in response to $9 / 11$. For that matter, things do not have to go wrong invariably or frequently-or even occasionally. One tidal wave of mass hysteria can bury due process. All the same, reactions to 9/11 were restrained and short-lived.

\section{Israel, 1980-2011}

Almost without exception, studies of mass reactions to terror attacks are studies of reactions to $a$ terror attack. The Second Intifada ground on year after year, for more than four years. The casualties on both sides were horrendous. It is not easy to imagine a more fear-inspiring terror than year-afteryear suicide bombings and rocket attacks. Peffley, Hutchison, and Shamir's (2015) study of political tolerance is thus unique, tracking levels of political tolerance in the Israeli public, over a three decade period, from 1980 to 2012, in the face of repeated and sustained terror attacks (Peffley, Hutchison, \& Shamir, 2015; Figure 2).

Their time series thus begins immediately after the First Intafada, runs through the whole of the Second Intifada, and continues for seven years after it. They found that levels of political tolerance were low at the beginning of the time series; steadily increased from 1993 through 2000; and thenin response to the Second Intifada, first stalled, then decreased Finally, with the end of the Second Intifada, political tolerance began, again, to increase.

Israelis respond to terror. "[T]he number of terrorist attacks before the survey," Peffley et al. (2015) observe, "was consistently the most reliable predictor of political tolerance over the time series" (p. 6). The previous increase in tolerance was first checked, then fell in the face of unprecedented

\footnotetext{
${ }^{5}$ In the contemporary era of short in-the-field internet surveys, the median time to complete interviews for a wave in this study was six months.

${ }^{6}$ See Davis (2007, Table 6.1, p. 119). Davis uses a cut-point of a difference of 5 percentage points or greater to mark significant wave-to-wave changes.
} 


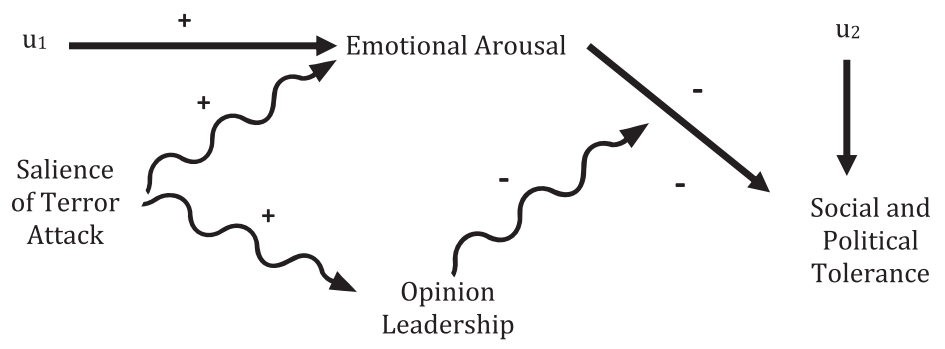

Figure 2. A model of perturbation effects

violence. The fall, however, was not precipitous. Moreover, the impact of terror on levels of tolerance was short-lived, decaying (on average) within three months. Finally, when the Intafada came to an end, levels of tolerance began again to increase. Taken as a whole, the Terror/Tolerance curve that Peffley et al. report is an example of a balanced-growth path. Over an extended period of time, levels of tolerance increase at (roughly) constant rate.

\section{Trust in Government}

Mass reactions to terror attacks in the form of increased trust in government deserve particular note. After a terror attack, citizens tend, unsurprisingly, to look to government for protection and responsive measures. But what opens the door to the use of authority opens it the abuse of authority. It is all the more worth underlining that increases in government tend to decay quickly. Exploiting five rounds of the European Barometer Study to analyze reactions of Spaniards to the 2004 Madrid train bombing (191 killed; about 2,000 injured), Dinensen and Jaeger (2013) surveyed trends in trust in 11 social and political institutions (e.g., the national government and political parties, the media, the police, trade unions.) The functional form of the 11 trend lines tracking trust is interchangeable: lower before the bombing; spiking immediately after the bombing; dropping to (approximately) prebombing levels at some point within seven months after the attack, and maintaining (again approximately) prebombing levels for the following year.

Dinenson and Jaeger's (2013) results should be interpreted with caution, for reasons beyond their control. The first survey ran from three weeks before the bombing to one week after the bombing. The next survey was fielded seven months after it. The sharpness of the surge to peak is a natural function of the proximity of the first measurement and the bombing. The seemingly similar sharpness of the postattack drop in trust may be an illusion. It could have happened at any point between the bombing and the interviews seven months later. The important point for our purposes is that, after seven months, levels of trust in institutions have returned to and remain at baseline through the end of the time series, a year and a half after the Madrid attack.

The results that we have reviewed point to a characteristic of public opinion that has not received quite the attention it deserves. Examined over broad intervals of time, attitudes on a variety of subjects, including immigrants, have more inertia than has been recognized. Examined over narrower stretches of time, the reactions of mass publics to terror attacks show some responsiveness. Research so far suggests that this responsiveness can be conceptualized as perturbations-that is, response curves, the peak of which is limited in size and time and the end of which is marked by a return to baseline values. Mass reactions do not always take this form, but they frequently, and on our reading of the research, regularly do. All the same, to call attention to the provisional status of this claim, we call it the "perturbation hypothesis." 


\section{A Heuristic Model}

Our objective is to describe a heuristic model of perturbation effects-that is, reactions of mass publics to terror attacks with a peak limited in size and time and an end marked by a return to baseline values.

The model is organized around two mechanisms: one that incites reactions to terror attacks ("emotional arousal") and one that inhibits them ("opinion leadership"). Formally, both of these mechanisms mediate mass reactions to terror attacks. A nonstandard feature of the model is that one of the mediators (opinion leadership) also moderates the other mediator (emotional arousal).

\section{Emotional Arousal}

Terror attacks excite responses, so a model of mass reactions to terror attacks requires an inciting mechanism. We conceptualize the inciting mechanism as emotional arousal.

The common practice is to identify a mechanism with a variable. Properly specified, mechanisms are themselves a causal process to model. Emotional arousal is a complex state. It involves, inter alia, reactions of anxiety, focusing of attention, and threat perception which themselves can be conditional on moderators (e.g., authoritarianism). ${ }^{7}$ The process of emotional arousal has a dynamic. Anger can feed on anxiety, anxiety on anger; and so long as the process continues, so, too, does a state of emotional arousal. But a state of emotional arousal is hard to sustain. Crises subside. The salience of a terror attack fades. The media turn to concerns and issues that are the regular stuff of headline news. Concerns and issues that are immediate and at the center of the lives of regular citizens call for their attention-making funds stretch to the end of the month, grappling with a child going through the challenges of adolescence; preparing for a wedding or a funeral. And as a state of arousal subsides, so, too, does its effects on people's attitudes and dispositions.

\section{Opinion Leadership}

To the extent that mass reactions to terror attacks are limited in degree and duration, an inhibiting mechanism is required. In our model, opinion leadership is the inhibitory mechanism.

A paradox led to its discovery. American presidents, it has long been known, enjoy a boost in popularity in the face of international crises (e.g., Mueller, 1973; Siegelman \& Conover, 1981). The paradox is that presidents can enjoy a popularity boost both when they succeed and when they fail. Both the Bay of Pigs and the Iranian hostage crisis, for instance, were manifest failures, but paradoxically both President Kennedy and President Carter enjoyed a surge in popularity in response to the two fiascos.

This may seem an easy paradox to resolve. In an international crisis, citizens naturally tend to "rally around the flag." And they will be as disposed to do so in response to a policy failure as to a policy success. This is an instructive example of how things go wrong because the obvious answer is too obvious. A "rally around the flag" was the obvious and standard answer, until Brody and Shapiro (1989) took a simple step. They made two lists, one of crises where the president enjoyed a surge of popularity, the other of crises where he didn't. What explained the difference between the two lists, they asked. Why do presidents benefit from some international crises but not others?

\footnotetext{
${ }^{7}$ With respect to authoritarianism, the intuition is that individuals' propensity to support government actions that prioritize national security over civil liberties depends on how predisposed they are to authoritarian responses in the ordinary course of affairs. The intuition is plausible, though it is necessary to note that it leads to two opposing lines of inquiry. One hypothesizes and finds evidence that high authoritarians react more strongly than low authoritarians to a terror attack. The other line of inquire hypothesizes and finds evidence of the opposite: that low authoritarians react more strongly than high authoritarians. This has proven to be a harder knot to untie than it may seem to be. Between modest effects and complex hypotheses, the results have been reliably mixed.
} 
Crises that require immediate responses are situations in which "there is no time for dissension to develop" (Waltz 1967, cited in Brody and Shapiro 1989, p. 87). The press of a significant threat, the importance of formulating a response, the control of governing elites over critical information, mean that opposition elites "have substantial incentive to remain silent or to be vaguely supportivesupport that later can be, and usually is, withdrawn - and almost no incentive to criticize" (Brody and Shapiro, 1989, p. 90). So far as this is so, media outlets tend to transmit a picture of a cross-party consensus, explicitly or implicitly backing leadership. Seeing a picture of consensus support, those who ordinarily disposed to criticize the president temper their critical impulses, and the president enjoys a popularity boost.

A key feature of this pattern of opinion leadership is that it tends to be self-limiting. Once the sense of crisis fades and/or the informational asymmetry between governing and opposing elites diminishes, the usual interparty conflict resumes, and citizens who had been inclined to temper their criticism of the president during the crisis return to their precrisis posture.

\section{A Simple Perturbation Model}

Two concerns have motivated studies of mass reactions to Islamic terror attacks. Will they trigger a backlash against Muslims either in the form of increased prejudice against them or decreased support for their civil liberties and civil rights? Will majority citizens respond to Islamic terror attacks by giving incumbents greater latitude to introduce policies and regulations that give priority to national security at the expense of individual liberties? Both concerns presuppose that changes in levels of tolerance take the form of perturbations-limited, even self-limiting disturbances.

On our reading of the research literature, the reactions of mass publics to terror attacks commonly, perhaps even characteristically, have a pair of features - a peak, which is limited in duration and degree, and an end marked by a return to baseline values ${ }^{8}$ We have called this a perturbation effect. In outline, we propose a dual-processing model, that is to say, outcomes are jointly dependent on automatic, affective responses and supervisory cognitive functions. Consistent with a standard dual-processing model, emotional responses automatically activated by a terror attacks, with some effort, can be subject to conscious control. ${ }^{9}$

Figure 2 displays a simple model of perturbation effects. A terror attack, we propose, is akin to an exogenous power surge. The surge has two effects, both temporary. One is to magnify the causal effect of emotional arousal on levels of political and social tolerance. The other is to activate opinion leadership, which in turn moderates the causal influence of emotional arousal on political and social tolerance. When the power surge subsides, outcomes again depend only on the underlying system of long-term causal influence before the attack.

All this we take to be uncontroversial. The contribution that the heuristic model in Figure 2 aims to make is to represent, simultaneously, the operation of long-term, steady-state system and, in response to the shock of a terror attack, the activation of a temporary short-term system. To distinguish short- and long-term, we introduce a graphical convention. Wavy lines represent short-term relations or shock effect; straight lines represent long-term or steady-state relations. Both wavy and straight lines are arrow-headed to signify that they represent causal relations.

Long-term effects. Figure 2 presents a radically abbreviated summary of the relationship of emotional arousal and political and social tolerance. The positively signed straight line from " $\mathrm{u}_{1}$ " to emotional arousal represents the steady-state (i.e., absent a terror attack) sources of emotional

\footnotetext{
${ }^{8} \mathrm{~A}$ return to baseline does not follow tautologically from a reaction limited in duration and degree. A return to baseline follows only once one rules out learning. Reactions to terror could well take the form of learning curves, where each trial lowers the threshold of an aversive reaction to a subsequent attack. On our reading of the research literature, the results argue strongly against cumulative effects. See especially Peffley et al. (2015).

${ }^{9}$ There is a large literature on dual-processing models, but the studies of Blinder, Ford, and Ivarsflaten (2013; Ivarsflaten, Blinder, \& Ford, 2010) have been our guide.
} 
arousal. The positively signed straight line from " $\mathrm{u}_{2}$ " represents the steady-state sources of political and social tolerance apart from emotional arousal. The negatively signed straight line from emotional arousal represents the steady-steady effect of emotional arousal on political and social tolerance - and a channel of influence to conduct the effect of a temporary heightening of emotional arousal in response to a terror attack on perception on social and political tolerance.

To represent the effects of the short-term shock of a terror attack, two mediators are required, one to supply a mechanism to account for emotional arousal or excitement effects; the other to provide a mechanism to account for inhibition or restraint effects. Consistent with a dual-processing approach, the first effect of the shock of the terror attack is a state of automatically activated emotional arousal, represented by a wavy arrow-headed line running from terror attack when salient to emotional arousal. Emotional arousal involves inter alia activation of affect, focusing of attention, and perception of threat. Emotional arousal is shorthand for a process. Its heightening in response to a terror attack is akin to a power surge. The effect is to magnify the effect of emotional arousal on political and social tolerance temporarily- "temporarily" being the operative word.

The second mechanism in the model is opinion leadership. An aim of the perturbation model is to represent constraints on opinion leaders. The key constraint is signaled in Figure 2 by the absence of a causal link-even a temporary one-between opinion leadership and emotional arousal. On this conception, political elites do not have the capacity to affect immediate emotional reactions to a terror attack. (This is a premise whose validity, going forward, is not guaranteed.) What political elites have the capacity to influence are behavioral impact of emotional arousal? Behavioral, to be clear, is being used permissively. Judgments of presidential performance or awarding latitude for governments to respond to terror are political behaviors. Consistent with the Brody-Shapiro model of opinion leadership, the stronger the impact of opinion leadership, the more moderate the effect of emotional arousal on political and social tolerance. This formalization of the mediational role of opinion leadership, it is worth noting, is an extension of prevailing practice in political psychology. Customarily dual mediator models represent mediators as independent mechanisms, each specifying a separate process converting cause into effect. In contrast, in the model in Figure 2, opinion leadership is mediator and moderator: The effect of emotional arousal is conditional on the impact of opinion leadership.

The combination of short- and long-term paths provides an account of peak and end reactions to terror attacks. Peak reactions are limited in duration because the salience of an attack dissipates over time and limited in degree because opinion leadership inhibits-inhibits not eliminates - the effects of emotional arousal. The end of reactions to terror attacks is marked by a return to baseline values because the impact of an attack diminishes as its salience diminishes leaving the long-term factors alone in operations. The result: Reactions of mass publics to terror attacks take the form of perturbations.

\section{Qualifications and Conclusions}

Existing research has focused on the excitement of reactions that terror attacks stimulate in mass publics. It has been our aim to call attention to their decay. Yes, the data are patchy, and yes, the results are not uniform. But the results that have accumulated so far point to the outlines of a phenomenon of the first order of importance to understand. Commonly, reactions of mass publics suggest response curve defined by two properties - a peak limited in duration and size and an end marked by a return to baseline values. We have labeled them perturbation reactions.

Formal analysis of the impact of perturbations presents challenges. The conventions of causal modeling in the study of politics and public opinion have been developed to represent the relations of relatively enduring dispositions to respond in particular ways-for example, to be susceptible to perceiving threats and therefore to be predisposed to support exclusionary policies. To represent the impact of a short-lived shock, it is necessary to develop models combining short-term and long-term 
systems of influences. To capture this distinction in graphical representations of causal models, we propose an amalgamation of straight arrow-headed lines to reflect relatively enduring causal influences and wavy arrow-headed lines to represent short-term influences.

More than one warning would likely be useful, but the most important is this-the elasticity of the term, short-term. Short-term is not a synonym for transitory. In the study of mass responses to terror attacks, reactions are characteristically measured in months and sometimes years. One implication is that the survey experiment, though useful in many ways, is of minimal use for studying the career of responses to terror events. The problem is not that responses to the treatments administered in a survey experiment are evanescent-or, as seems closer to the mark to us-specific to the circumstances in which the terms of the stimulus question has placed respondents. Many, perhaps most, are. The problem is that analysis of the decay of a response curve with an extended tail requires an extended sequence of surveys. Trend studies, or better still, survey panels are a necessary approach.

Reviewing research to this point, we would emphasize how much has been accomplished in the analysis of reactions to events whose location and timing are inherently unpredictable. Substantively, we believe that the results point to a primary pattern of reaction-limited and short-lived, perturbations as we have called them. So far as this is so, a path to a deeper understanding of the resilience of liberal democracies in the face of uncertainty and challenge opens up. There may, however, be more reason for caution than celebration. Terror attacks on a new scale or directed at a new target may trigger a new response. More ominously, the calculus of political power is at risk of changing. In an increasing number of countries in Western Europe, anti-immigration parties are now partners in governing coalitions, ${ }^{10}$ and even Pangloss would acknowledge that, in the United States, there is a leader capable of extremist reactions to terror attacks. Regrettably, Hume was right. Past regularities do not guarantee future outcomes.

\section{ACKNOWLEDGMENTS}

We acknowledge support from the Independent Research Fund Denmark (grant no. DFF-400300192B), and we thank Alex Pedersen for excellent research assistance. Correspondence concerning this article should be addressed to Paul M. Sniderman, Encina Hall West, Room 302, Stanford, CA 94305-6044.E-mail: paulms@stanford.edu

\section{REFERENCES}

Best, S., Krueger, B., \& Ladewig, J. (2006). The polls-trends: Privacy in the information age. Public Opinion Quarterly, 78, 375-401.

Blinder, S., Ford, R., \& Ivarsflaten, E. (2013). The better angels of our nature: How the anti-prejudice norm affects policy and party preferences in Great Britain and Germany. American Journal of Political Science, 57, 841-857.

Bonilla, T., \& Grimmer, J. (2013). Elevated threat levels and decreased expectations: How democracy handles terrorist threats. Poetics, 41, 650-669.

Brody, R. A., \& Shapiro, C. R. (1989). A reconsideration of the rally phenomenon in public opinion. Long Samuel (Ed.), Political Behavior Annual, 2, 77-102. Boulder, CO: Westview Press.

Davis, D. W. (2007). Negative liberty. New York, NY: Russell Sage.

Dinensen, P. T., \& Jaeger, M. M. (2013). The effect of terror on institutional trust: New evidence from the 3/11 Madrid terrorist attack. Political Psychology, 34, 917-926.

Hansen, B. T., Østergaard, S. D., Sønderskov, K. M., \& Dinesen, P. T. (2016). Increased incidence rate of trauma-and stressor-related disorders in Denmark after the September 11, 2001, terrorist attacks in the United States. American Journal of Epidemiology, 184(7), 494-500.

\footnotetext{
${ }^{10}$ The Progress Party in Norway, the Freedom Party in Austria, and La Lega in Italy, for instance, form part of the governing coalitions while the Danish People's Party is the supporting party for the center-right coalition government in Denmark.
} 
Ivarsflaten, E., Blinder, S., \& Ford, R. (2010). The anti-racism norm in Western European immigration politics: Why consider it and how to measure it. Journal of Elections Public Opinion and Parties, 20, 421-445.

Jenkins-Smith, H., \& Herron, K. (2005). United States public response to terrorism: Full lines or bedrock? Review of Policy Research, 22, 599-623.

Mueller, J. (1973). War, presidents and public opinion. New York, NY: John Wiley.

Peffley, M., Hutchison, M., \& Shamir, M. (2015). The impact of persistent terrorism on political tolerance: Israel, 1980 to 2011. American Political Science Review, 109, 1-16.

Siegelman, L., \& Conover, P. J. (1981). The dynamics of presidential support during international conflict situations. Political Behavior, 3, 303-318.

Sniderman, P. M., Petersen, M. B., Slothuus, R., \& Stubager, R. (2014). Paradoxes of liberal democracy: Islam, Western Europe and the Danish cartoon crisis. Princeton, NJ: Princeton University Press.

Sniderman, P. M., Slothuus, R., Petersen, M. B., Stubager, R., Ford, R., \& Sobolewska, M. (n.d.). Terror and tolerance: The challenge of inclusion of Muslims in Western Europe. In E. Borgida, C. Federico, \& J. Miller (Eds.) At the forefront of political psychology: Essays in honor of John L. Sullivan. New York, NY: Routledge.

Walz, K. (1967). Electoral punishment and foreign policy crises. In J. N. Rosenau (Ed.), Domestic sources of foreign policy (pp. 263-293) . New York, NY: Free Press. 